\title{
The prevalence of translocations in parents of children with regular trisomy 21: a possible interchromosomal effect?
}

\author{
R H LINDENBAUM*, M HULTÉN†, A McDERMOTT $\ddagger$, AND M SEABRIGHT \\ From the *Department of Medical Genetics, Churchill Hospital, Oxford; †West Midlands Regional \\ Cytogenetics Laboratory, East Birmingham Hospital, Birmingham; $¥$ South Western Regional Cytogenetics \\ Centre, Southmead Hospital, Bristol; and §Wessex Regional Cytogenetics Unit, Salisbury General Hospital, \\ Salisbury.
}

SUMMARY It has been suggested that translocations, and perhaps other chromosome rearrangements, disturb meiotic disjunction of uninvolved chromosome pairs and predispose to trisomic offspring. If so, then one would expect an excess of translocations not involving chromosome 21 among the parents of regular trisomic Down's syndrome patients. Such translocations have been reported, but mostly as anecdotal single case reports or very small series. In an attempt to collect a larger series, a collaborative study of regular Down's syndrome families was made in southern England. This was retrospective, and covered periods of 7 to 10 years since 1970. The number of regular trisomy families investigated was 1454 .

Only 945 of the 2908 parents were karyotyped, and 10 balanced reciprocal translocations not involving chromosome 21 were identified, together with one Robertsonian (13q14q). Expressing these as percentages of the parents tested (945), prevalences are as follows: reciprocals $1.06 \%$, Robertsonians $0 \cdot 11 \%$, and all translocations $1 \cdot 16 \%$. Expressed as percentages of the total parents (2908), tested and untested, the prevalences are $0.34 \%, 0.03 \%$, and $0.37 \%$ respectively. The 'true' prevalences, that is what would have been found had all parents been tested, must lie between these two sets of figures. The prevalence of reciprocal translocations exceeds that found for consecutive banded newborn infants, which is $0.16 \%$, and this excess may reflect a real interchromosomal effect. Robertsonian translocations in the banded newborn series are at a frequency of $0.11 \%$, identical to that found in the tested parents of regular trisomics. Interpretation of these figures is critically dependent upon the real prevalence of translocations among the newborn, estimates of which increase as technical methods are improving.

'Interchromosomal effect' implies an interactive disturbance of meiosis, whereby a structural chromosome rearrangement upsets disjunction or distribution of chromosome pairs not involved directly in the rearrangement and results in unbalanced or aneuploid gametes and offspring. Such an effect has been observed in Drosophila and in mouse translocations, and has been claimed to occur also in man..$^{1-3}$ Reports have been of single cases or very small series, and these reports are of little value in documenting this effect, which in man remains unproven. ${ }^{4-7}$ Aurias $e t a l^{8}$ documented five Down's

Received for publication 16 March 1984

Accepted for publication 18 May 1984 syndrome families with a balanced reciprocal trans- $\frac{D}{2}$ location not involving chromosome 21 from a total of 10000 karyotypes in their department. Stoll ${ }^{6} \mathrm{~N}$ claims 'interchromosomal effect' in four of the 40 ' reciprocal translocations reported from his laboratory.

The observation of four families with a regular trisomy 21 child and a parent with a balanced $\varphi$ reciprocal translocation not involving chromosome $\mathbb{\Phi}$ 21 , detected within the Oxford region during a decade, ${ }^{9}$ led to estimates of $0.68 \%(3 / 439)$ as the minimum prevalence of reciprocal translocations in $\frac{\mathrm{O}}{\mathrm{D}}$ Down's syndrome with regular trisomy, and $0.91 \%$ $(4 / 439)$ as the minimum prevalence of reciprocal $\stackrel{\perp}{\varrho}$ translocations in the mothers of such Down's 
syndrome cases. Exclusion of families in which the Down's syndrome proband was not karyotyped made the prevalence of balanced reciprocal translocations $1.24 \%$ in parents tested, or $0.52 \%$ per total parents, tested and untested. These figures greatly exceeded the then current estimate of $0.078 \%(1 / 1280)$ for the prevalence of balanced reciprocal translocations in the general population, ${ }^{4}$ and prompted extension of the Oxford study to regions immediately adjacent. Chromosome banding methods were employed during the greater part of the Oxford study period and the study periods within the neighbouring regions. This collaborative and retrospective study was set up expressly to examine prevalence of reciprocal translocations in parents of regular trisomics, but prevalence of Robertsonian translocations is also reported.

\section{Material and methods}

The initial Oxford study covered the years 1970 to 1980, during which 416 cases of Down's syndrome were karyotyped. Of these, 384 had regular trisomy 21 or mosaicism for $46 / 47,+21$ and were included in the analysis. The study was extended by examination of families karyotyped at Salisbury General Hospital, Salisbury, at Southmead Hospital, Bristol, and at East Birmingham Hospital, Birmingham, over approximately the same time period. All cases of regular trisomy 21 identified as routine service work within these regional cytogenetic laboratories within the periods quoted were included. Mosaics with a 46, normal $/ 47,+21$ karyotype were also included, as were other mosaics with a $47,+21$ cell line and a case of $48, X Y Y,+21$. In this way a further 1070 families were added to the analysis, making a total of 1454 (table 1).

Excluded from the study were all families in which the diagnosis of Down's syndrome was a purely clinical one and not confirmed by karyotyping, although in some cases one or both parents did have

TABLE 1 Numbers of cases studied by regions.

\begin{tabular}{lllll}
\hline Lab/region & Period & $\begin{array}{l}\text { Total Down's } \\
\text { syndrome }\end{array}$ & $\begin{array}{l}\text { Down's } \\
\text { syndrome with } \\
\text { rob/rcp/inv/r(21) }\end{array}$ & $\begin{array}{l}\text { Other Down's } \\
\text { syndrome }\end{array}$ \\
\hline Birmingham & $1974-1980$ & 190 & 12 & 178 \\
Bristol & $1974-1981$ & 400 & 19 & 381 \\
Oxford & $1970-1980$ & 416 & 32 & 384 \\
Salisbury & $1971-1980$ & 534 & 21 & 513 \\
Total & & 1540 & 84 & 1456 \\
\hline
\end{tabular}

The total of 1456 Down's syndrome without rob/rcp/inv/r(21) includes two families with pairs of affected sibs, so there are only 1454 parental pairs for study. chromosome examination. (There were, for example, combining Oxford and Birmingham figures, 94 mothers and 54 fathers of such untested Down's syndrome patients, all these parents having normal karyotypes but being excluded from analysis.) The study was set up to examine the prevalence of reciprocal translocations in the parents of regular trisomics, and where a reciprocal translocation was found in the Down's syndrome child, but the parents were not tested, the family was also excluded. Cases of reciprocal or Robertsonian translocations originally identified outside the study periods, but re-examined during these periods, would create obvious bias and were excluded. All cases with structural rearrangements involving chromosome 21 , such as reciprocal or Robertsonian translocations involving this chromosome, inversions of 21 , or a ring, were excluded; although not further subjected to analysis, such exclusions are listed. Inversions involving chromosomes other than 21 were not analysed, as we feared incomplete ascertainment, and the true population frequency of such inversions has perhaps been underestimated. ${ }^{10}$ Parental cases of sex chromosome aneuploidy were identified, but are not listed. For further information on exclusions see table 1 and the appendix.

\section{Results}

The results of the survey are listed, analysed, and compared in tables 2,3 , and 4 , and the details of individual translocation families and the manner of ascertainment are shown in the appendix.

The initial Oxford study covered 384 families with regular trisomy $21 ; 323$ parents were tested, among

TABLE 2 Numbers of parents tested and number of translocations found, excluding $t(21)$.

\begin{tabular}{llcccl}
\hline & Tested & Not tested & Total & No of rcp & No of rob \\
\hline Mothers & 545 & 909 & 1454 & 7 & 0 \\
Fathers & 400 & 1054 & 1454 & 3 & 1 \\
Total parents & 945 & 1963 & 2908 & 10 & 1 \\
\hline
\end{tabular}

Mothers: rcp included $1 ; 7,1 ; 17,1 ; 20,2 ; 4,6 ; 22,7 ; 11,9 ; 18$.

Fathers: rep included $3 ; 8,11 ; 22,18 ; 20$, $\operatorname{rob}(13 q 14 q)$.

TABLE 3 Prevalence of translocations in tested parents and total parents.

$\begin{array}{lll}\text { (a) The prevalence of rcp and rob in tested parents is as follows: } \\ \text { Tested mothers } & \text { rcp } 7 / 545=1 \cdot 28 \% & \text { rob } 0 / 545=0 \% \\ \text { Tested fathers } & \text { rcp } 3 / 400=0.75 \% & \text { rob } 1 / 400=0 \cdot 25 \% \\ \text { Tested parents } & \text { rcp } 10 / 945=1.06 \% & \text { rob } 1 / 945=0 \cdot 11 \%\end{array}$

(b) Prevalance expressed as per total parents, tested and untested, is as follows: Total mothers rcp $7 / 1454=0.48 \%$ rob $0 / 1454=0 \%$ $\begin{array}{lll}\text { Total fathers } & \text { rcp } 3 / 1454=0.21 \% & \text { rob } 1 / 1454=0.07 \%\end{array}$ Total parents $\quad$ rcp $10 / 2908=0.34 \% \quad$ rob $1 / 2908=0.03 \%$ 
TABLE 4 Balanced structural rearrangements ( $r c p$, rob) in neonatal and amniocentesis surveys, and in parents of regular trisomy 21 .

\begin{tabular}{|c|c|c|c|c|}
\hline \multirow[t]{2}{*}{ Author } & \multirow[t]{2}{*}{ Date } & \multirow{2}{*}{$\begin{array}{l}\text { Survey } \\
\text { size }\end{array}$} & rep & rob \\
\hline & & & No \% & No \% \\
\hline \multicolumn{5}{|c|}{ Consecutive newborn surveys } \\
\hline Hamerton et al $^{11 *}$ & up to 1975 & 46150 & $360.08 \%$ & $420.09 \%$ \\
\hline $\begin{array}{l}\text { Hamerton et al } \\
\text { Nielsen and }\end{array}$ & $1970-1973$ & 14069 & $110.08 \%$ & $130.09 \%$ \\
\hline Sillesen ${ }^{12}$ & 1971-1974 & 6099 & $70 \cdot 11 \%$ & $90 \cdot 15 \%$ \\
\hline Buckton et $a l^{13}$ & 1976-1977 & 3993 & $30.08 \%$ & $30.08 \%$ \\
\hline Hansteen et $a l^{14}$ & 1978-1979 & 1830 & $50.27 \%$ & $40 \cdot 22 \%$ \\
\hline \multicolumn{5}{|c|}{ Maternal age amniocenteses } \\
\hline van Dyke et al ${ }^{10}$ & $1978-1981$ & 8158 & $140 \cdot 17 \%$ & $90 \cdot 11 \%$ \\
\hline \multicolumn{3}{|c|}{$95 \%$ confidence limits banded newborn ${ }^{10}$} & $0 \cdot 01-\theta \cdot 19 \%$ & $0 \cdot 00-0 \cdot 13 \%$ \\
\hline \multicolumn{5}{|c|}{ Parents of regular trisomy 21, this study $1970-1981$} \\
\hline Parents: alVtested & & $2908 / 945$ & $100.34-1.06 \% 1$ & $10 \cdot 03-0 \cdot 11 \%$ \\
\hline Mothers: alVtested & & $1454 / 545$ & $70.48-1 \cdot 28 \% 0$ & $00 \%$ \\
\hline Fathers: all/tested & & $1454 / 400$ & $30 \cdot 21-0 \cdot 75 \% 1$ & $10 \cdot 07-0 \cdot 25 \%$ \\
\hline \multicolumn{5}{|c|}{ This study, excluding Oxford data } \\
\hline Parents: alltested & & $2140 / 622$ & $60.28-0.96 \% 1$ & $10 \cdot 05-0 \cdot 16 \%$ \\
\hline Mothers: alVtested & & $1070 / 364$ & $30.28-0.82 \% 0$ & $00 \%$ \\
\hline Fathers: all/tested & & $1070 / 258$ & $30 \cdot 28-1 \cdot 16 \% 1$ & $10.09-0.38 \%$ \\
\hline \multirow{2}{*}{\multicolumn{3}{|c|}{ Corrected prevalences-see Discussiont }} & & \\
\hline & & & $0.41-0.55 \%$ & $0 \cdot 10 \%$ \\
\hline
\end{tabular}

*Pooled data from earlier surveys, reported in Hamerton,"

†Adjusted to allow for the probable presence of translocations in some of the untested parents.

whom four balanced reciprocal translocation carriers were identified. Expressed per parents tested the prevalence of reciprocal translocations was $1 \cdot 24 \%$. Expressed per total parents, tested and untested, the prevalence was $0.52 \%(4 / 2 \times 384)$.

Extension of the study to the neighbouring regions added a further 1070 families. Among these were identified a further six balanced reciprocal translocations and a single Robertsonian (13q14q). Expressing these additional findings per parents tested the prevalence of reciprocal translocations was $0.96 \%$. Expressed per total parents, tested and untested, the prevalence was $0 \cdot 28 \%$. The prevalence of Robertsonian translocations not involving chromosome 21 was $0 \cdot 16 \%$ per parents tested, or $0.05 \%$ per total parents.

Combining Oxford and subsequent data, reciprocal translocation prevalence was $1.06 \%$ per tested parents, or $0.34 \%$ per total parents. Prevalence of Robertsonian translocations not involving chromosome 21 was $0 \cdot 11 \%$ per tested parents or $0.03 \%$ per total parents.

\section{Discussion}

Observation of the high figures for the Oxford region was the reason for extension of the study.
Exclusion of the Oxford results (table 4) shows the initial high frequency of balanced reciprocal translocations to be confirmed in a study of the adjacent regions.

As not all the 2908 parents were karyotyped the true figure for prevalence of reciprocal translocations must lie between the prevalence in tested parents and the prevalence in all parents, tested and untested (table 3 ).

In cases 1,7 , and 10 (appendix), although a reciprocal translocation was present in a parent, it had not been passed to the trisomic offspring. Since these three cases appeared among the 939 tested parents, we might expect to find among the 1963 untested parents a further six reciprocal translocations (that is, $1969 \times 3 / 939$ ), making the true prevalence $16 / 2908$, or $0.55 \%$ for all parents, mothers and fathers combined. Alternatively, if we argue that the untested parents carry balanced reciprocal translocations at the frequency found in the earlier newborn surveys (about $0 \cdot 1 \%$ ), the untested 1963 parents would carry just a further two translocations, making the count of balanced reciprocals $12 / 2908$, a frequency of $0.41 \%$. These 'corrected prevalences' are shown in table 4 , which also shows prevalence estimates for balanced reciprocal and balanced Robertsonian translocations, as made from consecutive newborn surveys. These figures are compared with frequencies found in maternal age amniocenteses, ${ }^{10}$ with the findings in parents of regular trisomy 21 , and the estimated 'corrected prevalences', as described above. Balanced reciprocal translocations appear to be over-represented in the Down's syndrome families (tables 3 and 4). Even the lower figures, as given in table 3(b) and in the left hand of the paired figures in the lower lines of table 4 , obtained by disregarding the possibility of untested parents being translocation carriers, lie above the $95 \%$ confidence limits of van Dyke et al, ${ }^{10}$ and are several-fold above those quoted in all newborn surveys except that of Hansteen et al. ${ }^{14}$ Crucial to any arguments about a possible interchromosomal effect are reliable figures for prevalence of translocations in the general population. It may yet prove that currently accepted figures considerably underestimate this incidence. The earlier newborn surveys were made without the benefit of banding. The later studies ${ }^{10} 14$ have suggested slightly higher figures, particularly for reciprocal translocations.

In contrast to the problem of determining the true prevalence of reciprocal translocations in a newborn or a parental population, the prevalence of Robertsonian translocations could be securely established even without banding. The general population prevalence of Robertsonian translocations lies close to $0 \cdot 11 \%$, of which no more than 
one-fifth $(0.02 \%)$ involve chromosome 21 . Unless, as seems unlikely, the prevalence in parents of Down's syndrome children lies below the general population prevalence there would be approximately two further Robertsonian translocations not involving chromosome 21 among the 1963 untested parents, that is, a total of $3 / 2908$ parents, which is $0 \cdot 10 \%$. Thus, the prevalence of Robertsonian translocations not involving chromosome 21 in parents of children with regular trisomy 21 lies close to the accepted general population mean.

The maternal age effect well recognised in Down's syndrome might be supposed to be absent when a parental reciprocal translocation contributed to the meiotic non-disjunction. Therefore, we might expect to find the reciprocal translocation group of parents younger, on average, than the other parents of regular trisomy 21 children. For the Oxford series of Down's syndrome (standard trisomy 21, excluding the reciprocal translocation families) the mean maternal age was 31.13 years (age recorded in 286 cases), and the mean paternal age was 32.60 years (age recorded in 164 cases). Table 5 lists the parental translocation carriers by age, together with the age of their spouses. Mean age of the maternal reciprocal translocation carriers was 28.07 years, and mean age of the paternal reciprocal translocation carriers was 28.5 years, figures which are well below the means for parents of Down's syndrome children (Oxford). The figure shows the ages of Oxford and other parental carriers of reciprocal translocations against a background of Oxford parents not carrying a reciprocal translocation, but with a Down's syndrome child, born within the region during the years 1970 to 1980 . The mean age of the four Oxford mothers with a reciprocal translocation was 29.0 years (whole year ages corrected by adding 0.5 years). No parents with a reciprocal translocation appear in the long 'tail' of older parents.

TABLE 5 Age at birth of Down's syndrome child, parents carrying reciprocal translocation, and their spouses.

\begin{tabular}{lll}
\hline Case No & Mother's age & Father's age \\
\hline 1 rcp & $27^{*}$ & 29 \\
2 rcp & 32 & $30^{*}$ \\
3 rcp & 37 & $31^{*}$ \\
4 rcp & 25 & $23^{*}$ \\
5 rcp & $22^{*}$ & 23 \\
6 rcp & $35^{*}$ & 34 \\
7 rcp & $24^{*}$ & 26 \\
8 rcp & $33^{*}$ & 40 \\
9 rcp & $22^{*}$ & 24 \\
10 rcp & $30^{*}$ & $?$ \\
11 rob & $?$ & $?$ \\
\hline
\end{tabular}

*Denotes the parent carrying a balanced translocation.
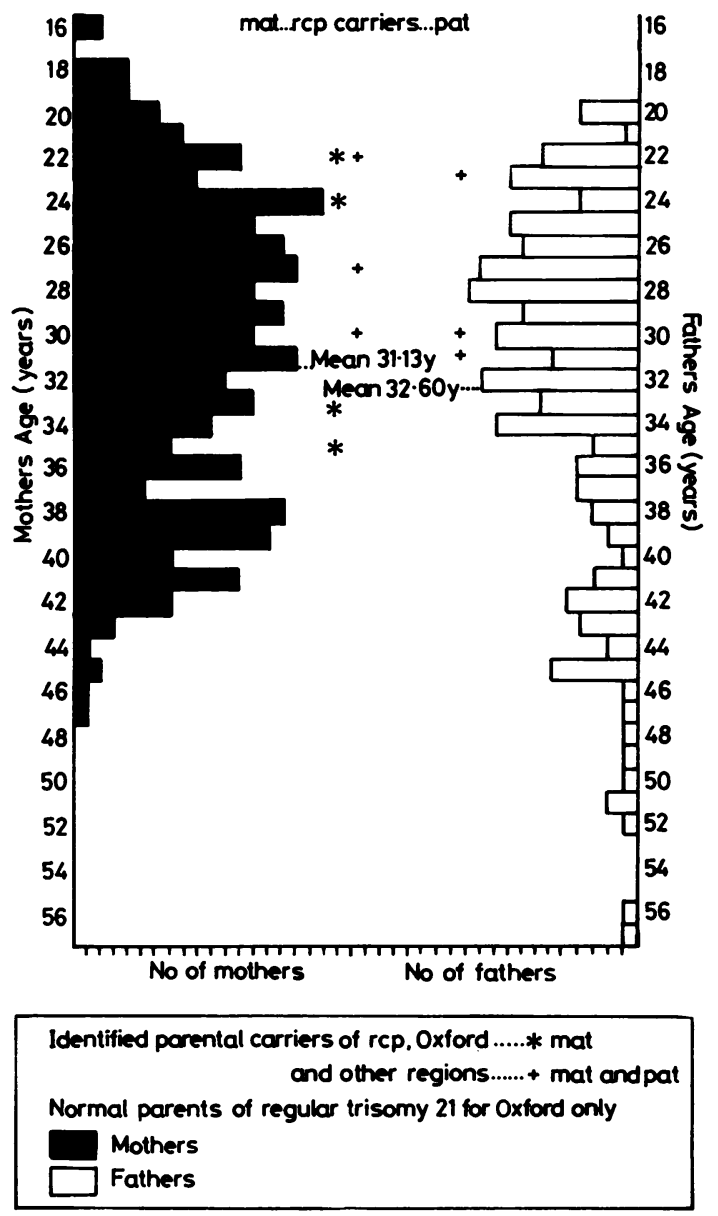

FIGURE Histogram showing distribution of maternal age and paternal age, where recorded, for the parents of regular trisomy 21 DS (Oxford only), and the age of rcp carrier parents of regular DS for Oxford and other regions. Mean maternal age and mean paternal age shown for Oxford parents only (mean $M A 31 \cdot 13$ y, $n=286, S D=6 \cdot 86$; mean $P A 32.60$ y, $n=164, S D=7.97)$.

Finding a high prevalence of reciprocal translocations in parents of standard trisomy 21 Down's syndrome does not necessarily imply that these translocations increase the likelihood of parental meiotic non-disjunction. Proof is still lacking that the parent carrying the reciprocal translocation was the parent in whom non-disjunction for chromosome 21 occurred, but it is planned to reinvestigate the reciprocal translocation families to decide this. The possibility of the reciprocal translocation inducing post-zygotic disjunctional errors cannot be excluded. One mosaic was identified among the 10 
cases of reciprocal translocation plus trisomy 21 reported here.

We wish to thank Dr Ann Chandley for encouraging extension of the initial study, and the following persons for their great help with the collection and correction of data: Dr Michael Creasey, Mrs Daisy Bickley, Mrs Phyllis Batts, Mrs Kath O'Brien, and Dr Nina Gregson.

\section{References}

1 Grell RF, Valencia JI. Distributive pairing and aneuploidy in man. Science 1964;145:66-7.

2 Grell RF. Distributive pairing in man? Ann Genet (Paris) 1971;14:165-71.

${ }^{3}$ Ford CE, Evans EP. Robertsonian translocations in mice: segregational irregularities in male heterozygotes and zygotic imbalance. Chromosomes Today 1973;4:387-97.

4 Jacobs PA. Structural rearrangements of the chromosomes in man. In: Hook EB, Porter IH, eds. Population cytogenetics: studies in humans. New York: Academic Press, 1977:81-97.

5 Stoll C, Flori E, Beshara D. Interchromosomal effect in balanced translocations. Birth Defects 1978;XIV(6C):393-8.

- Stoll C. Non-random distribution of exchange points in patients with reciprocal translocations. Hum Genet 1980;56:89-93.
${ }^{7}$ Hecht F. Familial sex chromosome mosaicism (yes) and interchromosomal effects (no). Clin Genet 1981;19:77-8.

${ }^{8}$ Aurias A, Prieur M, Dutrillaux B, Lejeune J. Systematic analysis of 95 reciprocal translocations of autosomes. Hum Genet 1978;45:259-82.

9 Lindenbaum RH. Reciprocal translocation and Down's syndrome: a possible interchromosomal effect. Clin Genet 1981;19:520-1.

10 van Dyke DL, Weiss L, Roberson JR, Ramesh Babu V. The frequency and mutation rate of balanced autosomal rearrangements in man estimated from prenatal genetic studies for advanced maternal age. Am J Hum Genet 1983;35:301-8.

"Hamerton JL, Canning N, Ray M, Smith S. A cytogenetic survey of 14,069 newborn infants. I. Incidence of chromosome abnormalities. Clin Genet 1975;8:223-43.

12 Nielsen J, Sillesen I. Incidence of chromosome aberrations among 11148 newborn children. Humangenetik 1975;30:1-12.

13 Buckton KE, O'Riordan ML, Ratcliffe S, et al. A G-band study of chromosomes in liveborn infants. Ann Hum Genet 1980;43:227-39.

14 Hansteen I-L, Varslot K, Steen-Johnsen J, Langard S. Cytogenetic screening of a new-born population. Clin Genet 1982;21: 309-14.

Correspondence and requests for reprints to Dr $\mathrm{R} \mathrm{H}$ Lindenbaum, Department of Medical Genetics, Churchill Hospital, Headington, Oxford OX3 7LJ.

APPENDIX Case reports.

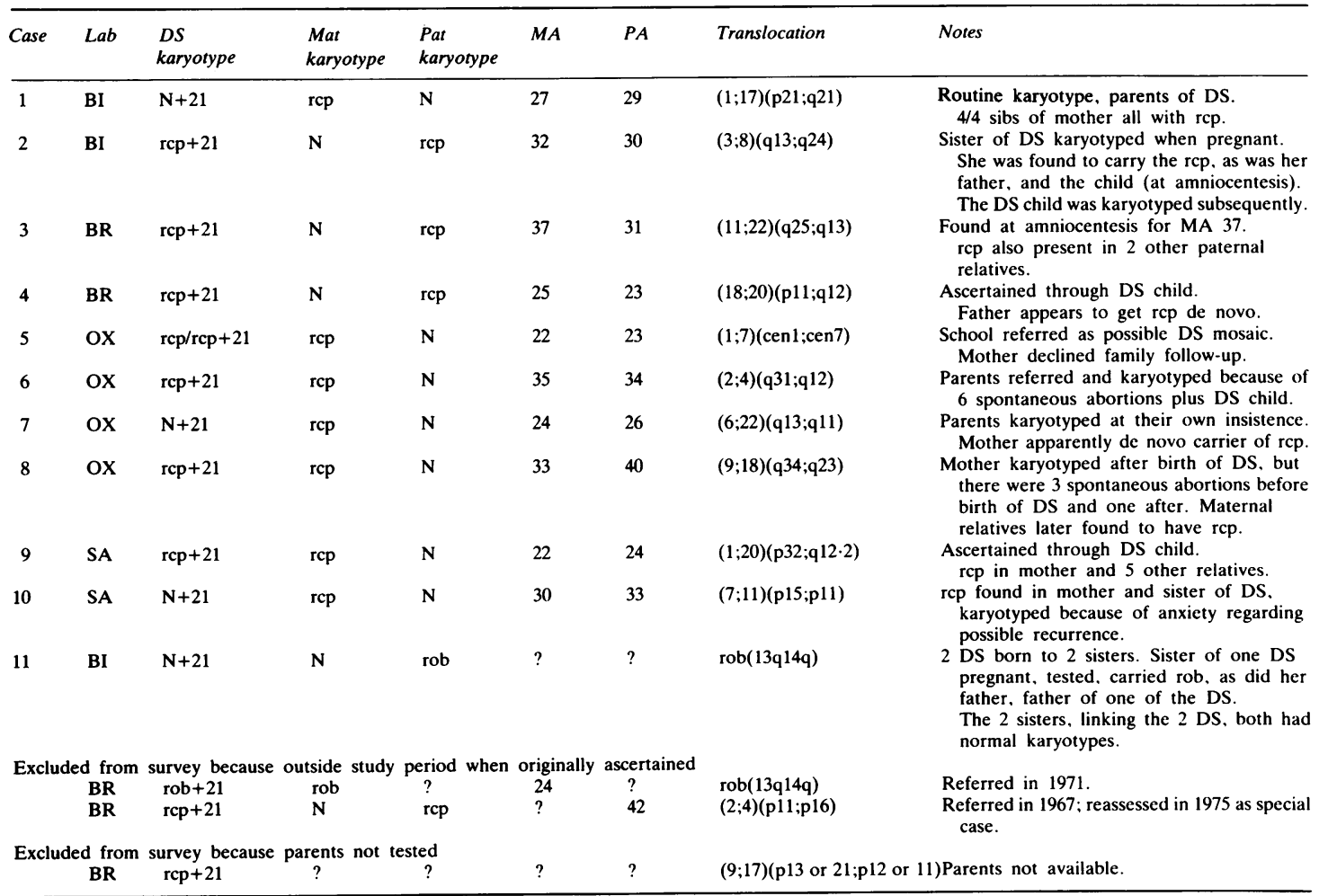

MA, PA = maternal, paternal age at birth of DS.

BI, BR, OX, SA = Birmingham, Bristol, Oxford, Salisbury.

$\mathrm{N}=$ normal, or no rcp/rob.

rcp, rob = balanced rcp, rob. 